\title{
The Negative Effects of Smart Phones on the Jordanian Children from the Perspective of Parents
}

\section{Fatima Abdelhadi Zainelabdin}

\author{
Assistant Professor, \\ Amman University College for \\ Financial and Administrative Sciences, \\ Amman, Jordan
}

DOI: https://doi.org/10.36941/jesr-2020-0095

Abstract

The study entitled "The Negative Effects of Smart Phones on the Jordanian Children from the Perspective of Parents" seeks to answer the following general question: What is the impact of using a smartphone on the socialization of Jordanian children from the perspective of parents? The descriptive study aimed to know the impact of using the smartphone on the socialization of the child and the nature of the values and behaviors acquired by the child as a result of using the smartphone. The researcher relied on the tools of scientific observation without the participation or a questionnaire was distributed on a sample estimated (30o) parents, using the intentional sample of parents, in Amman; the researcher has reached the following results: $66 \%$ of children always use a smartphone, $36 \%$ of children started their interest in the smartphone from 3 to 5 years, $52 \%$ of children take half an hour to an hour using a smartphone, 34\% of children use a smartphone depending on the circumstances, 39.33\% of the children had a poor concentration after using the smartphone, 53.33\% adopt negative behaviors as a result of using their smartphone, $48.66 \%$ of children become interacting with others after using the smartphone, 56.66\% of children have diseases after they used a smartphone, including autism. The study recommends: The need to activate the role of social institutions, especially the family through the protection of children from programs, videos and applications and awareness of the seriousness of what is provided in the smartphone, parents were keen to establish good social habits that contribute to the formation of the child's personality, as well as the development of an accurate and structured program for children on the hours and times of their use of the smartphone so as not to affect their school hours.

Keywords: Smart Phones, Children, social habits, positive values

\section{Introduction}

Today, we live in an age of technological evolution that has different expressions and nomenclature to describe it, these include the era of the global technical revolution, the era of information technology and technical explosion, this revolution contributed to the emergence of many achievements and inventions, including mobile phone, which has undergone many developments, down to being a smart phone (Al-Sabawi, 2006).

Smartphones have control a big part of our lives, and take up a lot of our time, scattered everywhere, in cities, villages, streets, high mountains and in all corners of our homes, the result of this deployment, the world is witnessing development in the telecommunications sector, every 
passing day a new invention, new applications and constant developments in communication devices are born which is today considered an important factor for many in their daily lives (Ahnieh, 2017).

In an era when information and communication technology has become the true proof of the advancement of infinite technology, which allowed the provision of many services in various fields, and exchange of information where today it is considered one of the most important outlets to communicate with others, which led to drift to the use of the means of communication and the media excessively (intact, 2015).

The name "Web" appears to be an accurate description, it shows the status of Internet users, and its impact on them, many people fall into endless nets, and driven to rely on it almost completely, and feel eager while they are disconnected from the internet, and try to break free from their responsibilities in order to spend more time browsing, thus, the individual loses his independence and becomes a slave to the Internet, which controls all the activities of his life (Arnott, 2007).

No sane person denies that smart phones are now playing a big role in people's lives, it has become a means of social communication, entertainment and knowledge, and as a result it has spread among children and teenagers remarkably, and their time with these devices has increased, prompting many specialists and guardians to sound the alarm about the negative effects of this use (Najjar, 2014).

Many children spend long hours on smartphones and tablets to the point of being addictive, so that getting them away from it becomes an increasingly difficult issue, while statistics show that 20 percent of parents don't monitor what their kids are browsing online, according to the survey, parents are unaware of the risks to children while using tablets and smartphones to surf the Internet without censorship (Dwikat, 2016).

At the same time, other parents are worried about their children's increased use of smartphones and their access to websites and download games, as well as the use of cameras and communicate with others via social networking sites.

Keeping children safe while using the Internet is a daunting task, especially when these children are out of sight of parents, and the task becomes even more difficult when parents want to know what children are doing (Dwikat, 2016).

Therefore, children's use of digital devices throughout the day leads to a decline in health safety standards such as completing homework, completing tasks, paying attention to learning and keeping calm in the face of challenges. This is what made a generation of zombies in the era of smart technology (AL-Hassi, 2017).

This study attempts to determine the impact of smart phones on children from the perspective of their parents by answering the questionnaire.

\section{$1.1 \quad$ Research problem}

Through personal observation or review of previous studies and literature, it has been noted that there are several problems associated with the use of children smartphones. Parents feel a sense of satisfaction, when they watch their little child control a device that some adults and people who aren't interested in technology can't handle, mothers may leave their children for hours in front of the phone screen, to find herself ample to work and relax away from disturbing her child, and the father may not notice the extent of his child's attachment to that device, because of his work, ignoring the psychological, social, educational, and even health damage to the lives of their children and their future.

By reviewing and reading Arab and foreign studies on the problem of children using smart phones, identify its negative effects on the child's social, health and behavioral life and the problems that he / she may suffer with his surroundings. 
The study is very important because of the topic that it dealing with, and it is the subject of excessive use of technology, which has become a concern for many groups of society and its negative effects on children in particular. For this issue there is an additional importance due to its modernity and the lack of scientific research treatments.

\subsection{Theoretical importance}

1. Identify the negative effects of the use of smart phones on children, which can cause longterm problems on their social, behavioral, health and scientific life.

2. This study contributes to the attention of parents, authorities and institutions concerned with the upbringing of children. To the need for limitations to the use of children for smart devices to the need for limitations to the use of children for smart devices.

\subsection{Applied importance}

1. Contribute to the creation of a viable environment for the education of the new generation, by providing research to the bodies concerned with children and their upbringing.

2. Students of elementary and special education sciences may benefit from the research.

3. The search results may provide a reference to other research in the same context.

1.5 Research goals

1. Detect the impact of smart devices on children.

2. Identify the extent to which mothers are aware of the effects on their children through the use of devices in the study community in the towns of Jaba and Bathan in the northern West Bank.

3. Direct parents to monitor what their kids are watching, in addition to educating them about the harmful use of phones to the scientific and social lives of their children, and parents will be able to set a time or number of hours of viewing. And control the quality of content that their children are exposed to.

\section{Previous Studies}

2.1 Shaheen study (2014) entitled: "The role of smart devices in family disintegration and juvenile delinquency"

The study aimed to identify the role played by smart devices, with family disintegration with its social, psychological and religious dimensions, and to show the role of smart devices on juveniles in terms of moral deviation and misdemeanors and crimes and identify an important issue which is the negative effects of smart devices. The study used the descriptive analytical method. A sample of (50) psychologists and social workers was used and persons with disabilities, including fractured families and juveniles at the Spring Foundation for the rehabilitation of juveniles in Gaza for the year 20152014. The study concluded that smart devices have a role in transforming couples into individuals who have no sense and reduce their sense of responsibility towards their families.

Al-Sabawi study (2006) aimed at revealing the most important social effects of mobile phone, that the mobile phone can leave, whether positive or negative, the sample of the research consisted of (150) individuals. The research also adopted the social survey methodology using the sample method and the questionnaire was used as a data collection tool. The research found that the mobile effects positive as well as negative revealed by search results. 
2.2 A study (Al-Ammar 2014) entitled: Internet addiction and its relationship with some variables among students of Damascus University - Daraa Branch.

The study aimed to define Internet addiction among Damascus University students in the light of the following variables: Gender (male and female), specialization, level of achievement, economic status, number of hours Sit down online, favorite sites. The analytical descriptive approach has been adopted. The distribution of the sample was normal and the sample was random and the number was (674) students from all colleges and institutes. The results were:

1. There is no relationship between Internet addiction and the academic average.

2. There was a significant positive correlation between Internet addiction and the economic situation.

3. There is no significant difference in Internet addiction attributable to the gender factor.

4. There is no significant difference in internet addiction attributable to the major, only some differences between the arts students on the one hand and education, rights, science and economics on the other hand in favor of students of literature.

5. The average sitting in front of the computer network was 2.78 degrees per day out of four.

6. Social sites topped all sites in terms of percentage of visitors.

2.3 Al- Jamal Study (2014), entitled: "The Negative Effects of Smartphones on Student Behaviors from the Perspective of Educational Advisors and Principals in Southern Hebron"

The study aimed to identify the negative effects of smart phones on the behavior of students from the perspective of educational counselors and principals in southern Hebron. The study used the descriptive analytical method. A questionnaire consisting of (20) items was distributed on four sides, and the sample size was $(54.2 \%)$.

Among the most important results of the study are the following:

1. Smart phones have a negative impact on the behavior of students from the point of view of counselors and principals in southern Hebron.

2. It was also found that there are no statistically significant differences in the negative effects of smart phones on the behavior of students from the point of view of counselors and principals in southern Hebron.

2.4 Abu al-Rab and al-Qusairi's study (2014) entitled: "Behavioral problems caused by the use of smartphones by children from the perspective of parents in light of some variables"

The study aimed to identify behavioral problems caused by the use of smart phones by children from the perspective of parents in the light of some variables. The study was applied to a sample of (112) parents of children they were randomly selected. The study members responded to a questionnaire prepared to achieve the objectives of the study consisting of three dimensions (social, psychological, educational) and after analysis the results show that the most common behavioral problems are social problems, followed by behavioral problems and psychological problems. It was also found that there are statistically significant differences in behavioral problems due to the use of smart phones attributed to gender in favor of males, and that there are differences due to age in favor of the age group (2-18) years, in the number of hours of use for the category (1-3) hours and (more than 3 hours) and based on the results of the study, a set of recommendations aimed at reducing these problems.

2.5 Divan study 2012: The effect of cellular devices on the appearance of behavioral problems in a sample of children.

The aim of the study was to identify the effect of cellular devices on the appearance of behavioral problems. The study was conducted on children aged 7 years. The study sample consisted of (320oo) 
children, the mothers of the children filled out a special questionnaire. The results of the study showed that children using cellular devices are more likely for the emergence of behavioral problems such as nervousness, mixing fluctuations, mental straightness, dullness and other problems, compared to children who are not using cell phones, these problems also increase as the child uses cell phones at an early age.

\section{Methodology}

\subsection{Socio-demographic characteristics of the study sample}

This theme deals with the characteristics of the respondents, which are presented in tables 1 to 4

Table 1: Shows the gender variable of the sample

\begin{tabular}{lcc}
\hline Gender & Repetition & Ration \\
\hline Male & 140 & $\% 46.66$ \\
Female & 160 & $\% 53.33$ \\
\hline Total & 300 & $\% 99.33$ \\
\hline
\end{tabular}

By reading the above table, which represents the gender of the respondents, we find that 160 individuals, and by (53.33\%) of them are female, The equivalent of 140 individuals, and by (46.66\%) males, hence the proportion of females (mothers) is high compared to males (parents) and this is due to the fact that mothers are closest to their children compared to parents and this is the result of parents' preoccupations where they are often away from home.

Table 2: Represents the educational level

\begin{tabular}{lcc}
\hline Educational level & Repetition & Ratio \\
\hline Basic stage & 14 & $\mathbf{4 . 6 6 \%}$ \\
Secondary & 60 & $\mathbf{2 0} \%$ \\
Tawjihi & 66 & $\mathbf{2 2 \%}$ \\
Diploma & 80 & $\mathbf{2 6 . 6 6 \%}$ \\
Bachelor & 80 & $\mathbf{2 6 . 6 6 \%}$ \\
\hline Master degree & $\mathbf{3 0 0}$ & $\mathbf{1 0 0} \%$ \\
\hline
\end{tabular}

We can see from the table that the ratio of (26.66\%) brought together bachelor and master, which is the largest proportion, followed by an average of (22\%), and not much different from the (20\%) for the secondary level, finally, (4.66\%) for the basic level, this confirms to us and says that the study sample of the educational level at a level between bachelor and master, which drives it to pay attention to modern technology.

Table 3: Represents the standard of living

\begin{tabular}{lcc}
\hline Standard of living & Repetition & Ratio \\
\hline Weak & 34 & $\mathbf{1 1 . 3 3 \%}$ \\
Medium & 198 & $\mathbf{6 6 \%}$ \\
Good & 68 & $\mathbf{2 2 . 6 6 \%}$ \\
\hline Total & $\mathbf{3 0 0}$ & $\mathbf{1 0 0 \%}$ \\
\hline
\end{tabular}

By reading the above table, which represents income or standard of living, it is clear that the majority of families or parents have an average economic level, representing (66\%).As for the parents with 
good income was $(22.66 \%)$, followed by (11.33\%) for low-performing parents. It turns out that this variable was chosen in order to find out which category most adopt smartphones in terms of income level or economic level, thus we conclude that the standard of living in the Arab world is average over the next twenty years, agriculture first of all requires that it produce enough food for the population in terms of governance, quality and standard of living.

Table 4: The number of children per household

\begin{tabular}{ccc}
\hline Number of children & Repetition & Ration \\
\hline 1 & 12 & $4 \%$ \\
2 & 82 & $27 \cdot 33 \%$ \\
3 & 92 & $30.66 \%$ \\
4 & 114 & $38 \%$ \\
\hline Total & 300 & 100 \\
\hline
\end{tabular}

By reading the table above, which represents the number of children within each household, it was found that (38\%) represented 4 children, followed by (30.66\%) represented by 3 children, as for the presence of two children, the percentage was (27.3\%) and lastly (4\%), with one child.

The number of children in each household can be linked to the standard of living of the family (economic level). And it may be related to educational level, reproduction also requires logical mental foundations for example, some of them associate it with the economic level, possible to be on the submission of a housing file, the situation requires a large number of children in order to achieve and accept the file and get housing, thus, the less offspring, the greater the interest of parents in their children and fulfilled their demands.

\section{Results of Study}

4.1 The child's use of the smartphone:

This theme deals with the habits and patterns of child use of the phone, which are presented in the tables extending from Table 5 to Table 10.

Table 5: The child's use of the telephone

\begin{tabular}{lcc}
\hline Usage & Repetition & Ratio \\
\hline Always & 198 & $66 \%$ \\
Sometimes & 62 & $20.66 \%$ \\
Scarcely & 40 & $13.33 \%$ \\
Total & 300 & $98 \%$ \\
\hline
\end{tabular}

The results of the above table show that $(66 \%)$ of the respondents confirmed the permanent use of the smart phone by their children. While (20.66\%) said their children sometimes use a smart phone, finally, (13.33\%) are rare. It turns out that children use the smart phone on a permanent basis because of it contains games and pictures. It arouses the interest of the child, fulfills his desire and strengthens his future personality to become a natural phenomenon accepted by parents in society.

Table 6: The child's attention to smart phone

\begin{tabular}{lcc}
\hline Years & Repetition & Ratio \\
\hline From 3 to 5 years & 108 & $36 \%$ \\
From 6 to 8 years & 114 & $34 \%$ \\
From 9 to 11 years & 78 & $26 \%$ \\
Total & 300 & $100 \%$ \\
\hline
\end{tabular}


By reading the table above, which represents the age at which the child began to care about the smart phone, it is clear to us that children aged between 3 and 5 years were estimated at (36\%) which is the highest percentage, while children aged 6-8 years are estimated at (34\%). Children aged between 9 and 11 were estimated at $(26 \%)$.

It is clear from the above that the child began to take care of the smartphone at an early age and this is due to the availability of this technology (smartphone) at home, which is a way to draw attention in children since childhood because of the content and games in it. And other videos and applications and easy to get.

Table 7: The length of time it takes the child to use the phone

\begin{tabular}{lcc}
\hline Time & Repetition & Ratio \\
\hline Less than half an hour & 90 & $30 \%$ \\
Half an hour to an hour & 158 & $\mathbf{5 2 . 6 6 \%}$ \\
More than two hours & 52 & $\mathbf{1 7 . 3 3 \%}$ \\
\hline Total & 300 & $100 \%$ \\
\hline
\end{tabular}

By reading the table above which represents the time it takes a child to use a smartphone, it turns out that the time spent by the child on using the phone from half an hour to an hour was estimated at (52.66\%), less than half an hour was 30\%, followed by more than two hours and it was estimated at $(17.33 \%)$.

We can see from the above that the child uses the smartphone from half an hour to an hour due to the failure of parents to monitor their children, some parents, for example, want to get rid of the inconvenience of their children, they resort to their involvement in watching programs on television, or play a particular game, etc.

Table 8: Represents periods of child's use of a smartphone

\begin{tabular}{lcc}
\hline Periods & Repetition & Ratio \\
\hline Early morning & 26 & $\mathbf{8 . 6 6 \%}$ \\
Noon & 32 & $10.66 \%$ \\
Evening & 70 & $23 \cdot 33 \%$ \\
Night & 52 & $17.33 \%$ \\
Depending on the circumstances & 102 & $34 \%$ \\
\hline Total & $\mathbf{2 8 2}$ & $\mathbf{9 4} \%$ \\
\hline
\end{tabular}

The table shows that (34\%) of respondents confirmed that their children use a smart phone according to the circumstances. While $(23.33 \%)$ indicated that their children use the smart phone in the evening and (17.33\%) and (10.33\%) use their smart phone at night and at noon and (8.66\%) said their children were using a smart phone early in the morning.

It turns out that children use a smartphone according to circumstances more than the rest or the time available, and this shows that they have no particular time to use, whenever they have access to smartphones usage increased, and the lack of use in the morning for children who study because of their preoccupations with the study.

Table 9: Shows the days allocated for smartphone use by children

\begin{tabular}{lcc}
\hline Allocated days & Repetition & Ratio \\
\hline Week days & 118 & $39 \cdot 33 \%$ \\
Holidays & 182 & $\mathbf{6 0 . 6 6 \%}$ \\
\hline Total & 300 & $100 \%$ \\
\hline
\end{tabular}


By reading the table above which shows the days allocated for the use of the smartphone by children, the rate was $(60 \%)$, representing the percentage of children using a smartphone on holidays and the percentage of children who use a smartphone on weekdays is $(39.33 \%)$.

We find that the majority of children use the smartphone on the holidays any time in their spare time and discharge the burden of study for a whole week and we find them resorting to the phone to entertain themselves from an entire week full of study, homework, etc., and children who use the phone on weekdays. Their rate is not much less than the duration of use on holidays and this is what we can associate with what the parents said earlier in the neglect of their children to their duties and abandon it.

Table 10: Shows with whom the child uses the smartphone

\begin{tabular}{lcc}
\hline With who he uses it & Repetition & Ratio \\
\hline With parents & 140 & $46.66 \%$ \\
Alone & 110 & $36.66 \%$ \\
With friends & 50 & $16.66 \%$ \\
\hline Total & 300 & $100 \%$ \\
\hline
\end{tabular}

By reading the table above which shows the parents' observation and changes in the behavior of the child due to their use of the smartphone, it is clear that most parents notice changes in their children's behavior accounting for (90\%), while (57\%) of those who did not notice a change in their children's behavior as a result of using a smartphone, and $90 \%$ are due to the popularity of the device itself in the family and children which has become competing with adults in excessive use, this leads to a negative and positive impact on them, which changes some of their behaviors.

\subsection{The nature of behaviors acquired by the child:}

This theme deals with the nature of behaviors acquired by the child after using the smartphone, which are presented in the tables extending from Table 11 to Table 19.

Table 11: Illustrates the nature of the behavior acquired by the child after using the smartphone

\begin{tabular}{lcc}
\hline Acquired Behaviors & Repetition & Ratio \\
\hline Isolation and introversion & 78 & $\mathbf{2 6 \%}$ \\
Poor concentration & 88 & $\mathbf{3 9 \cdot 3 3 \%}$ \\
Late in talking & 60 & $\mathbf{2 0} \%$ \\
Aggressive & 58 & $\mathbf{1 4} \%$ \\
Others & 16 & $\mathbf{5 \cdot 3 3 \%}$ \\
\hline Total & $\mathbf{3 0 0}$ & $\mathbf{1 0 0} \%$ \\
\hline
\end{tabular}

By reading the table above it is clear that the child after using the smartphone. Became weakly focused by (29.33\%), secluded and folded. the percentage was $26 \%$, the delay of speech was estimated at $(20 \%)$ followed by aggression by $(14 \%)$ and the rest was the other little.

We have learned from the foregoing that the seating of children using a smartphone makes the child weak focus, secluded and folded and this is due to his addiction and continued use throughout his return from school or otherwise, as well as aggression that may be inside the house or outside his actions towards others. 
Table 12: Parents' satisfaction or otherwise on their child's use of a smartphone

\begin{tabular}{lcc}
\hline Are you satisfied & Repetition & Ratio \\
\hline Yes & 108 & $36 \%$ \\
No & 192 & $\mathbf{6 4} \%$ \\
\hline Total & 300 & $100 \%$ \\
\hline
\end{tabular}

By reading the above table, which shows whether or not parents are satisfied with their children's use of the smart phone, (64\%) represents the parents' lack of conviction and satisfaction with their children's use of the smart phone, compared to (36\%) representing parents who are satisfied with their children's use of the smart phone.

Parents' dissatisfaction may be based on convincing arguments against their children's use of a smart phone. Which can be more negative than positive, here; dissatisfaction can be traced back to the educational level. Parents can be illiterate i.e. not aware of the pros and cons of a smart phone and its applications, unlike parents with a high level of education, the idea of the phone and use by the child is different from the uneducated.

Table 13: The nature of the child's behavior

\begin{tabular}{lcc}
\hline Nature of behaviors & Repetition & Ratio \\
\hline Negative & 160 & $53.33 \%$ \\
Positive & 138 & $46 \%$ \\
\hline Total & 298 & $99.3 \% 3$ \\
\hline
\end{tabular}

By reading the table above which represents the nature of behaviors, it is clear that the negative behaviors acquired by the child by using the smart phone was estimated at (53.33\%) and positive by $(46 \%)$, from the above, we find that the nature of behaviors acquired by the child as a result of his use of the smart phone is negative and this is due to the nature of use itself by the child, in facilities and topics are not beneficial.

Table 14: Illustrates the positive behaviors that a child may adopt as a result of using a smartphone

\begin{tabular}{lcc}
\hline Positive behaviors & Repetition & Ratio \\
\hline Interact with others & 146 & $\mathbf{4 8 . 6 6 \%}$ \\
Frequent activity & 60 & $\mathbf{2 0} \%$ \\
Discipline and calm & 48 & $\mathbf{1 6 \%}$ \\
Acquiring learning skills (talk) & 46 & $\mathbf{1 5 . 3 3 \%}$ \\
\hline Total & 300 & $\mathbf{1 0 0} \%$ \\
\hline
\end{tabular}

By reading the table above which represents the nature of the child's positive behaviors as a result of using the smart phone, it is clear to us that the child became interacting with others and was estimated at (48.66\%), much activity was $(20 \%)$, quiet and disciplined by $(16 \%)$, and the behavior of skills acquisition was like learning by $(15 \cdot 33 \%)$.

From all of the above, we find that the interaction of the child with others due to the phone opens the child's wide horizons for learning and to learn about the cultures of others, and generates a love of research and reconnaissance and gain speed skills and strengthen his mind and this makes him active and vital and calm. 
Table 15: Shows if the child's use of the smartphone has caused a problem to him

\begin{tabular}{lcc}
\hline A problem & Repetition & Ratio \\
\hline No & 130 & $43 \cdot 33 \%$ \\
Yes & 170 & $\mathbf{5 6 . 6 6 \%}$ \\
\hline Total & 300 & $100 \%$ \\
\hline
\end{tabular}

By reading the table above which shows if the child's use of the smartphone has caused a problem or if it has created a problem for him / her, the answer was yes. May cause (56.66\%) of problems for children, and the answer is offset by a blame of (43.33\%).

Most of the parents reported that the smart phone caused problems for their children and this may be caused by permanent or excessive use among the diseases that reported autism, delayed speech, isolation, etc.

Diseases are not easy to treat, all this is due to the guardians of not monitoring the giving of the smartphone under the pretext of preoccupation or silence.

Table 16: Parents' monitoring of their children while using smart phones

\begin{tabular}{lcc}
\hline Monitoring & Repetition & Ratio \\
\hline Always & 90 & $30 \%$ \\
Sometimes & 114 & $38 \%$ \\
Never & 78 & $\mathbf{2 6 \%}$ \\
\hline Total & 300 & $\mathbf{1 0 0} \%$ \\
\hline
\end{tabular}

By reading the table above, which is the parent monitoring of children while using the smartphone, it is clear that most parents monitor their children while using the smartphone sometimes and it is estimated at $(38 \%)$, while we note that there are parents who are constantly monitoring their children and it was estimated at $(30 \%)$, and the latter shows that those who watch their children rarely account for $(26 \%)$.

From the above we reach that parents are monitoring their children while they use the smartphone sometimes this is due to busy parents work or lack of awareness of the negatives and risks of the phone or, they may monitor their children while using the phone, realize the effects and negative points involved in the misuse of the phone.

Table 17: Shows the child's reaction while preventing him from using the phone

\begin{tabular}{lcc}
\hline Reaction & Repetition & Ratio \\
\hline Crying & 76 & $\mathbf{2 5 . 3 3 \%}$ \\
Screaming & 34 & $\mathbf{1 1 . 3 3 \%}$ \\
Fracturing & 6 & $\mathbf{2 \%}$ \\
Noise & 26 & $\mathbf{8 . 6 \%}$ \\
Protest & 80 & $\mathbf{2 6 . 6 6 \%}$ \\
Stealing the Phone & 28 & $\mathbf{9 . 3 3} \%$ \\
Using another phone & 50 & $\mathbf{1 6 . 6 6 \%}$ \\
\hline Total & 300 & $\mathbf{1 0 0} \%$ \\
\hline
\end{tabular}

By reading the table above, which represents the reaction of the child while preventing him from using the smartphone; it shows us that accounted for $(26.66 \%)$ was the reaction of the kids. By protesting on the phone, followed by $(25.66 \%)$ their reaction is crying, of the children who reacted by resorting to another phone, the percentage was estimated at $16.66 \%$.This is followed by (11.33\%) of children who shout if you remove the phone from them, and the rate was (9.33\%) for children who steal the phone stealthily, then it was followed by $(8.66 \%)$. Children who make noise when you 
remove the smartphone from them, finally, cracking comes as a reaction of children by $(2 \%)$.

From this we find that children vary and proportions vary from one child to another. Protest is the first reaction of children in order to express their anger about the removal of the smartphone from them, each of them a way to express his anger or the like or the opposite, and this is because they are accustomed to a particular print that is difficult to give up easily.

Table 18: Parents' fear of using a smartphone

\begin{tabular}{lcc}
\hline Feeling scared & Repetition & Ratio \\
\hline Yes & 204 & $\mathbf{6 8 \%}$ \\
No & 96 & $\mathbf{3 2} \%$ \\
\hline Total & $\mathbf{3 0 0}$ & $\mathbf{1 0 0 \%}$ \\
\hline
\end{tabular}

Reading the table above, which shows the parents' fear because of the child's use of the smart phone; it is clear that parents are afraid of their children using the smart phone, where the rate was estimated at (68\%), and the percentage of those who do not have any fear of $(32 \%)$.

From the above we conclude that parents have fear of using their children for a smart phone, and this is due to the fact that it is a double-edged sword that has its advantages as well as some negative aspects. When dealt with negatively and for fear of negative use and excessive because it will open to the child a worldwide it is not commensurate with the size of the responsibility felt and the damage it affects on the psychological, social and health side.

Table 19: The parents' fear about their children using their smartphone

\begin{tabular}{lcc}
\hline Options & Repetition & Ratio \\
\hline Neglecting the study & 144 & $48 \%$ \\
Eye damage & 116 & $38.66 \%$ \\
Addiction & 40 & $13 \cdot 33 \%$ \\
\hline Total & 300 & $100 \%$ \\
\hline
\end{tabular}

By reading the table above, it is clear that parents are afraid Because of the child's use of the smartphone; this is due to the impact of the smartphone neglecting children to study, which was estimated at (48\%) and damage to the eyes by $38.66 \%$, and addiction to the smartphone by (13.33\%).

We conclude from the above that parents fear of the smartphone because of the neglect of the study and damage to the eyes due to the small size of the screen and they try to get the phone closer to the eye as much as possible to play and read the content. This causes fatigue to the eye and to keep it for a long time in a concentrated area.

\subsection{The nature of the acquired values}

In this axis we look at the negative and positive values acquired by the child, which are presented in the tables extending from Table 20 to Table 24.

Table 2o: The values that the child acquires between positive and negative

\begin{tabular}{lcc}
\hline Positive values & Repetition & Ratio \\
\hline Yes & 208 & $69.33 \%$ \\
No & 92 & $30.66 \%$ \\
\hline Total & 300 & $100 \%$ \\
\hline
\end{tabular}

By reading the table above which shows the child has gained some positive values as a result of using 
the smartphone, respondents asserted that their children have positive values of (69.33\%), while the opposite is (30.66\%).This is because the smartphone offers positive values and habits that the child tries to imitate through the games he plays through this smartphone. For example, the game of football, which shows the values associated with football games, namely, beware of (competing players) and sacrifice for the team and perseverance, as well as systems of play, and intelligence and adaptation in dealing with various new play situations.

Table 21: Shows that a smartphone can be considered as a catalyst in influencing a set of positive values in a child

\begin{tabular}{lcc}
\hline Positive values & Repetition & Ratio \\
\hline Yes & 188 & $62.66 \%$ \\
No & 112 & $37.33 \%$ \\
\hline Total & 300 & $100 \%$ \\
\hline
\end{tabular}

It is clear from the table above that the smartphone is a catalyst in instilling positive values in the child, where it was estimated at (62.66\%), while the opposite was (37.66\%).

From the above, we find that the smartphone is a catalyst in instilling the positive values of the child and this is due to the tremendous technological development that led to the emergence of new institutions that occupied the status of family, school, friends and mosques .One such technology is a smartphone that educates a child on certain values, habits and behaviors.

Table 22: Illustrates what excessive and continuous use of a smartphone by a child leads to

\begin{tabular}{lcc}
\hline Positive values & Repetition & Ratio \\
\hline Bad manners & 100 & $33 \cdot 33 \%$ \\
Abandonment of duties & 200 & $66.66 \%$ \\
\hline Total & 300 & $100 \%$ \\
\hline
\end{tabular}

Through our reading of the above table, the sample respondents confirmed that the continuous use of the child's smartphone leads to his negligence in duties and the ratio was estimated at (66.66\%). Offset by bad morals and deterioration by (33.33\%).

Thus, the continuous use of the child's smartphone makes him excessive in performing and answering it by distracting him and wasting his time and postponing his work by sitting on the phone in things that may be less important than performing his or her duties and this may affect educational attainment for specific years (non-students not involved), as for bad ethics is the result of misuse that leads to wrongdoing. We find that his use of the smartphone opens his eye on things that do not fit with his age and lost the innocence of the child and lives at the age of more than his age.

Table 23: The potential of the phone and its advantages as an effective part in the adoption of the child some educational, cultural, and ethical values

\begin{tabular}{|l|c|c|}
\hline Phone as an assistant & Repetition & Ratio \\
\hline Always & 36 & $12 \%$ \\
\hline Sometimes & 240 & $80 \%$ \\
\hline Never & 24 & $8 \%$ \\
\hline Total & 300 & $100 \%$ \\
\hline
\end{tabular}

Through our reading of the table above, which shows whether the phone that has contributed and helped the child in his adoption of educational, cultural and moral values, the percentage of those who adopt these values is sometimes $(80 \%)$, this is followed by $(12 \%)$ who always adopt, and $(8 \%)$ 
never adopt any values.

From the above we reach that the most important values, whether educational, cultural, moral, this is due to the roles offered by the smartphone may be educational or ethical, through reincarnation and imitation of what the phone offers, the adoption of these values is through the experiences of the child and experiences experienced during the socialization practiced by many institutions, including the smartphone as a modern technological element.

Table 24: Shows the child's practice of imitating what they see through a smartphone

\begin{tabular}{lcc}
\hline Child resort to imitation & Repetition & Ratio \\
\hline Always & 26 & $17 \cdot 33 \%$ \\
Sometimes & 103 & $\mathbf{6 8 . 6 6 \%}$ \\
Never & 21 & $14 \%$ \\
\hline Total & 150 & $100 \%$ \\
\hline
\end{tabular}

It is clear from the results of the table that $(68.66 \%)$ of respondents confirmed that their children's simulate their kids for a smartphone sometimes, while (17.33\%) indicated that they are permanent and $14 \%$ never and we conclude that children imitate what they see in the smartphone because his mind is not fully developed does not differentiate between what is negative and what is positive and this is what the theory of social learning talked about.

\section{Findings and Recommendations}

\subsection{Findings}

Through the above, the researcher reached the following:

- Parents of children are well aware of the negative effects of their children's use of smartphones.

- The use of smart phones has negative effects on children in terms of social, health, and behavioral aspects, from the viewpoint of parents.

- There is an effect of smart devices in weakening the child's skills in communicating with others and making him shy, introverted and neglected to some extent, and the smartphone works to draw a virtual world for the child away from his reality.

- The phone causes problems and pain in the neck and head.

- Using the phone causes the child to become inactive and lazy.

- Smartphone use can cause many diseases.

- The child seeks to imitate what he sees on the phone screen.

- The child becomes nervous when leaving the phone.

- The child has violent and cruel behaviors.

- The child rebels and doesn't listen to the instructions.

- A smartphone keeps the child away from his parents and siblings.

\subsection{Recommendations}

- Increase the level of control over the content that children follow.

- Determine the hours the child uses the smartphone.

- Instruct children to the correct use of smartphones.

- Instruct children to sit properly to avoid neck and head pain.

- Trying to occupy the child's time by doing activities away from the use of a smartphone, in order to develop his practical skills and refine his personality in line with the reality he is experiencing. 


\section{References}

Ahnieh, A. (2017) The negative effects of smart phones on the results of school pupils.

Alamaar, Kh. (2014) Internet addiction and its relationship to some variables among the students of Damascus University, Daraa Branch

Al-Jamal, S. (2014) The negative effects of smart phones on the behavior of students from the point of view of educational counselors and school administrators in southern Hebron

Al-Najjar, M. (2014) Children's Use of Smartphones Benefits and Precautions, 2014. at the link: https://goo.gl/UsqCQ2

Arnout, Bushra Ismail (2007), Internet addiction and its relationship to both personal dimensions and mental disorders in adolescents, Journal of the Faculty of Education, Zagazig University, No. 55.

ElhamMostafa et al., (2014), Behavioral problems caused by the use of smart phones by children from the perspective of parents in the light of some variables, International Journal of Behavioral Research, No. 35, UAE University.

Encyclopedia of the island, smartphone, The whole world with one device 2017, https://goo.gl/cGKChm

Habash, M. (2017) Smartphone Sales Growth to 380 Million Devices in Q1, at the link: https://goo.gl/K8zHa8

Mark et at (1998). Viewing Preferences symptoms of Psychological, - Singer and Violent Behaviors among children who watch television. Journal of the, Trauma American of child and Adolescent Psychiatry. Oct. Vol.37 (10): 1041-1048

Olsen J. (2012). Cell phone use and behavioral, Obel C, Kheifets L, -Divan HA 529-9 Divan HA., 66 (6), problems in young children. J Epidemiol Community Health

Sabawi, H. (2005) Social effects of mobile phone, Conductivity studies. Number Fourteen 2005.

Shaheen, S. (2014) The role of smart devices in family disintegration and deviation of events.

Shawabkeh, M. (2017) the benefits of smart devices, at the link: https://goo.gl/3R1Rz7.

Wikipedia, Descriptive analytical method, https://goo.gl/N6YXd5

\section{Websites}

Children's use of smartphones..functions and caveats 2017, link: http://goo.gl/iHfu4s.

IsraaHusni, Study the number of smartphone users to reach - 6 billion within 4 years, 2016, Link: https://goo.gl/ydTfy9.

ISDL, Online Safety Report, 2015, LIN, https://goo.gl/MpNQ44.

Tawfiq Katie. Civilized Dialogue "Number 3346, 2011, link: https://goo.gl/Mza6rA.

HamoudaSalima, Online Addiction: Disease of the Age, 2015 Journal of Humanities and Social Sciences. Number 21 - Algeria at the link: https://goo.gl/LfSBh8.

Hikmat al-Hassi, How to deal with children in technology, 2017at the link: https://goo.gl/2TK $7 y 1$.

Sana Dweikat, Impact of Technology on Children, 2017, at the link https://goo.gl/gkkLGH.

Ola Abayat, what is the meaning of smartphones, 2017.https://goo.gl/WVxs8j. 